\title{
Improving Toughness of PH13-8 Stainless Steel through Intercritical Annealing
}

\author{
Z. GUO, W. SHA, E. A. WILSON"1) and R. W. GREY
}

School of Civil Engineering, Queen's University of Belfast, Belfast, BT7 1NN, UK. Email: w.sha@qub.ac.uk

1) Emeritus Fellow, School of Engineering, Sheffield Hallam University, UK.

(Received on February 10, 2003; accepted in final form on April 10, 2003)

\begin{abstract}
An intercritical annealing step was introduced in the treatment of a $\mathrm{PH} 13-8$ stainless steel to improve the toughness of the alloy in aged condition. Four different treatment cycles, i.e. austenitisation (Q-treatment) and intercritical anneal (L-treatment), LQ, 2B (QLQL) and 2K (LQLQ) were carried out before aging treatment at $510^{\circ} \mathrm{C}$ for $4 \mathrm{~h}$ (the commercial $\mathrm{H} 950$ treatment). Optical and scanning electron microscopies, and Xray diffraction analysis were employed to study the microstructures of the alloys after different heat treatments. Hardness and Charpy impact strength of the samples were measured.

Results show that significant grain refinement was observed after $2 \mathrm{~K}$ and $2 \mathrm{~B}$ treatment, but not after $\mathrm{QL}$ and LQ treatments. Such refinement of prior austenite grain did not lead to significant increase of hardness either before or after ageing. The Charpy impact strength of the alloy in aged condition was improved after the four pre-ageing treatments. The formation of a 'dual-phase' martensitic structure through intercritical annealing is thought to make the main contribution to the better toughness obtained, with beneficial effects also from grain refinement. All the four treatments offer better combined properties than the commercial treatment, whereas QL and LQ treatments may be cost-competitive. Relationships among heat treatment, microstructure and mechanical properties are discussed.
\end{abstract}

KEY WORDS: stainless steel; toughness; grain refinement; intercritical annealing; heat treatment.

\section{Introduction}

PH13-8 stainless steel is a martensitic precipitation hardening $(\mathrm{PH})$ steel. It has high strength and hardness with good levels of resistance to both general corrosion and stress corrosion cracking. In addition, the alloy exhibits good ductility and toughness in large sections, and offers a high level of useful mechanical properties under severe environmental conditions superior to PH17-4 and PH15-5 stainless steels. It has been used for many applications, such as landing gear parts, nuclear reactor components and petrochemical applications requiring resistance to stresscorrosion cracking. ${ }^{1)}$. The commercial treatment that provides the best strength level is the $\mathrm{H} 950$ treatment, i.e. ageing at $510^{\circ} \mathrm{C}$ for $4 \mathrm{~h}$. However, the toughness property, reflected by the Charpy impact strength is relatively low. When better toughness is required, the alloy has to be treated differently where toughness is improved at the cost of strength. It is attempted in this research to improve the toughness without significant reduction in the strength, so as to maximize the potential of this alloy.

Grain refinement is the most effective way to simultaneously improve materials' strength and toughness. The wellknown Hall-Petch relationship, which predicts an increase in yield strength and a decrease in the ductile-brittle transition temperature (DBTT) with a decrease in grain size, has been shown to be applicable to a wide variety of metals. The principle of the beneficial effect of small grain size on impact toughness is valid for all metallic materials, but it is especially important for steels having a tendency of poor toughness at low temperatures. While thermomechanical processing can achieve very fine grain sizes, purely thermal treatments are also of considerable interest since these can be applied to thick plates and weldments. There has been extensive research on the topic of grain refinement through thermal treatments. ${ }^{2-10)}$ A common practice is thermal cycling, which was developed and first applied to $\mathrm{Fe}-12 \mathrm{Ni}-$ $0.25 \mathrm{Ti}^{2}{ }^{2} \mathrm{Fe}-8 \mathrm{Ni}-2 \mathrm{Mn}-0.25 \mathrm{Ti}^{3)}$ and $9 \mathrm{Ni}^{4}$ ) steels. Similar treatments were carried out independently on Fe-8Mn by Hwang and Morris ${ }^{5)}$ and Nasim and Wilson, ${ }^{6}$ resulting in considerable grain refinement and improvement in toughness. Attempts were also made to improve the mechanical properties of maraging steels such as 350-grade ${ }^{7)}$ and 300grade $^{8)}$ through thermal cycling. However, in the above work, ${ }^{2-8)}$ the toughness properties were improved due to the combined contribution of the retained/reverted austenite and grain refinement, usually at the expense of strength properties. In a recent work on a 250 -grade maraging steel, the prior austenite grain was refined to about $6 \mu \mathrm{m}$ after thermal cycling with no formation of reverted austenite. ${ }^{9)}$ Both strength and ductility properties of the alloy in both unaged and aged condition were effectively improved. The beneficial effect on strength due to grain refinement was amplified by ageing treatment. An earlier work on $18 \mathrm{Ni}$ grade-250 and grade-300 maraging steels also reported that thermal cycling could refine the prior austenite grain size. ${ }^{10)}$ 
Table 1. Chemical composition of the PH13-8 Mo steel.

\begin{tabular}{|c|c|c|c|c|c|c|c|c|c|c|c|c|c|c|}
\hline & $\mathrm{C}$ & $\mathrm{Al}$ & $\mathrm{Cr}$ & $\mathrm{Mo}$ & $\mathrm{Ni}$ & $\mathrm{Ti}$ & $\mathrm{Si}$ & $\mathrm{Co}$ & $\mathrm{Mn}$ & $\mathrm{Zr}$ & $\mathrm{P}$ & $\mathrm{S}$ & $\mathrm{N}$ & $\mathrm{Fe}$ \\
\hline $\mathrm{wt} \%$ & 0.03 & 0.97 & 12.43 & 2.15 & 8.39 & 0.067 & 0.07 & 0.01 & 0.02 & 0.004 & 0.006 & 0.002 & 0.001 & bal. \\
\hline at\% & 0.19 & 2.02 & 13.36 & 1.36 & 7.96 & 0.184 & 0.17 & 0.01 & 0.02 & 0.002 & 0.005 & 0.004 & 0.004 & bal. \\
\hline
\end{tabular}

Such grain refinement increased the strength of the alloy at room temperature, and a significant increase in ultimate tensile strength was observed at elevated temperatures. Recently Guo et al. reported that introducing an intercritical annealing step before the solution treatment of AerMet $100(\mathrm{Fe}-13.4 \mathrm{Co}-11.1 \mathrm{Ni}-3.1 \mathrm{Cr}-1.2 \mathrm{Mo}-0.23 \mathrm{C}$ in $\mathrm{wt} \%)$, a high strength lath martensitic steel, may result in fine effective grain size. ${ }^{11)}$ It should be noted that when maraging steels, i.e., martensitic precipitation hardening steels were studied, ${ }^{7-10)}$ attempts on grain refinement was through rapid austenitisation procedures, whereas studies on other alloys employed intercritical annealing in their thermal treatments. $^{2-6,11)}$ In the latter cases, even when tempering treatments were included, ${ }^{3,4)}$ the purpose was to introduce thermally stable austenite but not to achieve precipitation hardening. The grain size was retained through the tempering step. ${ }^{3,4)}$ It is not yet clear how the introduction of intercritical annealing will affect the precipitation kinetics and mechanical properties of precipitation hardening steels.

The aim of the current research was to refine the grain size of PH13-8 stainless steel through the introduction of intercritical annealing treatment. The influence of thermal treatment on grain size, mechanical properties of the alloy before and after ageing, and precipitation kinetics was studied. The relationships among heat treatment, microstructure, and mechanical properties are also discussed.

\section{Experimental Procedures}

\subsection{Alloy Composition and History}

The composition of the material studied is given in Table 1 in both wt $\%$ and at $\%$. The material was vacuum induction melted plus vacuum arc remelted (VIM/VAR) to a $500 \mathrm{~mm}$ ingot, homogenised at $1250^{\circ} \mathrm{C}$ for $12 \mathrm{~h}$, forged from $1100^{\circ} \mathrm{C}$ to $280 \mathrm{~mm}$ diameter, reheated to $1150^{\circ} \mathrm{C}$ and forged to $146 \mathrm{~mm}$ diameter, cooled to below $90^{\circ} \mathrm{C}$, and annealed between 650 and $720^{\circ} \mathrm{C}$. They were then solution treated at $1050^{\circ} \mathrm{C}$ for $2 \mathrm{~h}$ followed by water quenching (WQ), with no refrigeration. Blocks of size about $12 \times 12 \times$ $12 \mathrm{~mm}$ were cut from the material in this condition for this research. A layer of $1 \mathrm{~mm}$ was removed from the sample surface to avoid the possible influence of oxygen when specimens were characterised or tested.

\subsection{Intercritical Annealing and Experimental Design}

The heat treatments that are commonly used to refine the effective grain size of lath martensitic steel are variations on a single theme. ${ }^{12,13)}$ The alloy is quenched to martensite, and then reheated to accomplish a partial or complete reversion to the austenite phase. The re-heating causes one of four characteristic reactions, which are labelled in the schematic phase diagram in Fig. 1: tempering (t), intercritical tempering $(\mathrm{T})$, intercritical annealing $(\mathrm{L})$, and austenite

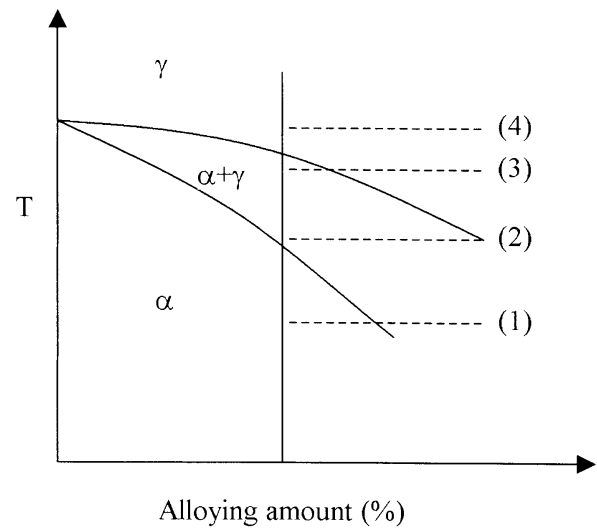

Fig. 1. Schematic phase diagram with four heat treatment temperatures used for (1) tempering, (2) intercritical tempering, (3) intercritical annealing, and (4) austenitising.

Table 2. Experimental design of the grain refinement heat treatments. All the treatments were followed by ageing at $510^{\circ} \mathrm{C}$.

\begin{tabular}{|c|c|l|}
\hline $\begin{array}{c}\text { Specimen } \\
\text { label }\end{array}$ & $\begin{array}{c}\text { Treatment } \\
\text { label }\end{array}$ & Treatment procedures \\
\hline 1 & Q & 0.5 hour at $927^{\circ} \mathrm{C}$, followed by water quenching (WQ) \\
\hline 2 & QL & 0.5 hour at $927^{\circ} \mathrm{C}(\mathrm{WQ})$, followed by 2 hours at $760^{\circ} \mathrm{C}(\mathrm{AC})$ \\
\hline 3 & LQ & 2 hours at $760^{\circ} \mathrm{C}(\mathrm{AC})$, followed by 0.5 hour at $927^{\circ} \mathrm{C}(\mathrm{WQ})$ \\
\hline 4 & $\begin{array}{c}2 \mathrm{~B} \\
\text { (QLQL) }\end{array}$ & $\begin{array}{l}0.5 \text { hour at } 927^{\circ} \mathrm{C}(\mathrm{WQ}), 2 \text { hours at } 760^{\circ} \mathrm{C}(\mathrm{AC}) \text {, and } 0.5 \text { hour at } \\
927^{\circ} \mathrm{C}(\mathrm{WQ}), \text { followed by } 2 \text { hours at } 760^{\circ} \mathrm{C}(\mathrm{AC})\end{array}$ \\
\hline 5 & $\begin{array}{c}2 \mathrm{~K} \\
\text { (LQLQ) }\end{array}$ & $\begin{array}{l}2 \text { hours at } 760^{\circ} \mathrm{C}(\mathrm{AC}), 0.5 \text { hour at } 927^{\circ} \mathrm{C}(\mathrm{WQ}) \text {, and } 2 \text { hours at } \\
760^{\circ} \mathrm{C}(\mathrm{AC}), \text { followed by } 0.5 \text { hour at } 927^{\circ} \mathrm{C}(\mathrm{WQ})\end{array}$ \\
\hline
\end{tabular}

formation $(\mathrm{Q})$. Detailed discussion of the four treatments can be referred to in Ref. 13). Intercritical annealing is used to denote a treatment just below $\mathrm{A}_{\mathrm{c} 3}$, in the upper part of the two-phase region.

Differential scanning calorimetry (DSC) is used to measure the transformation temperatures of the PH13-8 stainless steel. The DSC curve at heating rate $20^{\circ} \mathrm{C} / \mathrm{min}$ gives temperatures $\mathrm{A}_{\mathrm{c} 3}=800^{\circ} \mathrm{C}$ and $\mathrm{A}_{\mathrm{c} 1}=511^{\circ} \mathrm{C}$. The intercritical annealing temperature was set as $760^{\circ} \mathrm{C}$ in the present work, and the austenitisation temperature at $927^{\circ} \mathrm{C}$. The grain refinement treatments designed were shown in Table 2. Ageing at $510^{\circ} \mathrm{C}$ was carried out after these treatments. For Vickers hardness test, samples were aged at $510^{\circ} \mathrm{C}$ for 1, 4, 8, 15, $30 \mathrm{~min}, 1,2,4$ and $8 \mathrm{~h}$. Each sample was sealed in a quartz tube with vacuum for the ageing treatment. The hardness measurement was carried out on a Vickers hardness machine, with $2 \mathrm{~kg}$ working load. For Charpy impact test, specimens were aged at $510^{\circ} \mathrm{C}$ for $4 \mathrm{~h}$ (the commercial H950 treatment) in a salt bath. To conserve material, halfsize specimens were used for Charpy impact test, which are of $5 \times 10 \times 55 \mathrm{~mm}$ (half of the standard $10 \times 10 \times 55 \mathrm{~mm}$ 


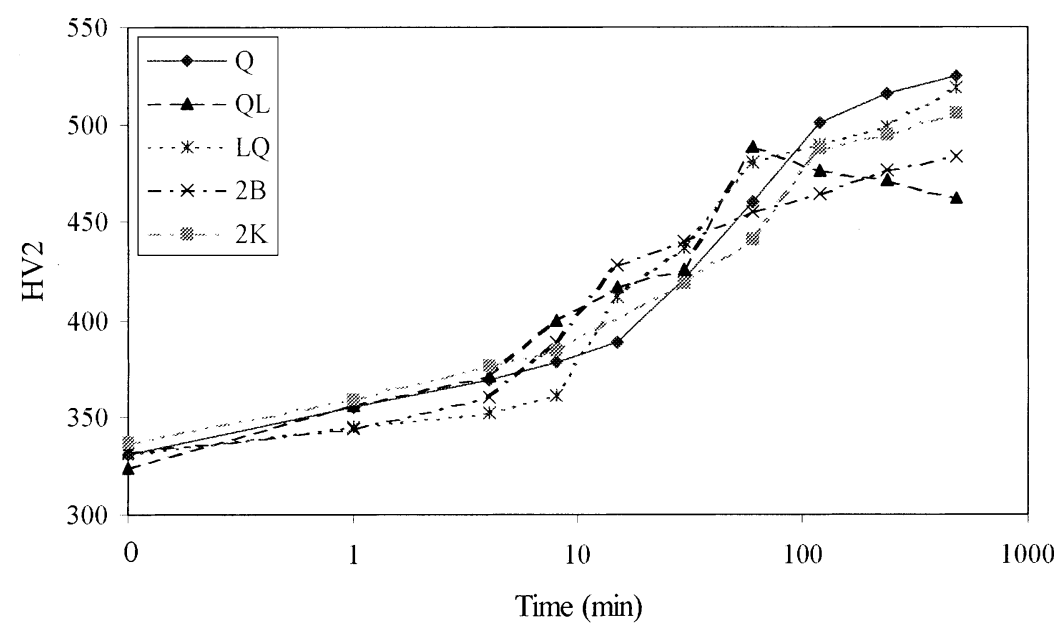

Fig. 2. Age hardening of the specimens subjected to different grain refinement treatments at $510^{\circ} \mathrm{C}$.

size), with $\mathrm{V}$-notch on the $5 \times 55 \mathrm{~mm}$ surface.

Optical microscope $(\mathrm{OM})$ and scanning electron microscope (SEM) were used to record the microstructure. Two types of etching method were attempted: chemical etching and electro-etching. The chemical etchant used was the Fly's agent ( 5 grams $\mathrm{CuCl}_{2}$ in $40 \mathrm{ml} \mathrm{HCl}$ acid, $25 \mathrm{ml}$ ethanol, and $30 \mathrm{ml}$ water). Although this etchant could reveal some microstructure feature of the specimens, the grain boundaries could not be observed clearly. Electroetching was carried out in a solution of $60 \mathrm{ml} \mathrm{HNO}_{3}$ acid and $40 \mathrm{ml}$ water to reveal the grain boundaries. With platinum cathode, the voltage and current were $0.4 \mathrm{~V}$ (DC) and $0.05 \mathrm{~A} / \mathrm{cm}^{2}$, respectively. The electro-etching time was 5-10 s. High resolution X-ray diffraction (HRXRD) analysis using synchrotron radiation and normal X-ray diffraction (XRD) analysis were used to detect the existence of retained/reverted austenite. For normal XRD analysis, specimens were scanned using a Siemens diffractometer applying $\mathrm{Cu} \mathrm{K}_{\alpha 1+\alpha 2}$ radiation (wave length for $\mathrm{K}_{\alpha 1}: 1.54056 \AA$ ) with a step size $0.02^{\circ}$. HRXRD analysis used radiation of wave length $1.29898 \AA$, also with a step size $0.02^{\circ}$.

\section{Result Analysis}

\subsection{Hardness and Charpy Impact Strength Measure- ments}

The age hardening kinetics at $510^{\circ} \mathrm{C}$ after the alloy was subjected to different thermal treatments are displayed in Fig. 2. Each data point is the average of at least six measurements. As can be seen from Fig. 2, the ageing time to reach peak hardness position is significantly shortened to $1 \mathrm{~h}$ by QL treatment, but the peak hardness value, HV 482, is lower than alloys after other treatments. The age behaviours of alloys after Q, LQ, 2B and $2 \mathrm{~K}$ treatments are similar, though the achievable peak hardness values may be different. The Charpy impact strength of samples aged for $4 \mathrm{~h}$ at $510^{\circ} \mathrm{C}$ after different treatments was given in Table 3, together with the hardness values before and after ageing for $4 \mathrm{~h}$. Only two Charpy impact strength data were the average of two measurements; the others were from one measurement. The scatter of the Charpy impact values is about 1-3 J. As Q treatment is a standard procedure before ageing in commercial treatments, the mechanical properties after
Table 3. Charpy impact toughness of samples aged at $510^{\circ} \mathrm{C}$ for $4 \mathrm{~h}$ after different heat treatments, together with the hardness values before and after ageing.

\begin{tabular}{|c|c|c|c|c|c|c|}
\hline $\begin{array}{c}\text { Treatment before } \\
\text { ageing }\end{array}$ & $\begin{array}{c}-78^{\circ} \mathrm{C} \\
(\mathrm{J})\end{array}$ & $\begin{array}{c}-40^{\circ} \mathrm{C} \\
(\mathrm{J})\end{array}$ & $\begin{array}{c}22^{\circ} \mathrm{C} \\
(\mathrm{J})\end{array}$ & $\begin{array}{c}100^{\circ} \mathrm{C} \\
(\mathrm{J})\end{array}$ & $\begin{array}{c}\mathrm{HV} \text { after } \\
\text { ageing }\end{array}$ & $\begin{array}{c}\text { HV before } \\
\text { ageing }\end{array}$ \\
\hline $\mathrm{Q}$ & & & $5.5 \pm 0.7^{*}$ & 32 & $516 \pm 9$ & $331 \pm 3$ \\
\hline $\mathrm{QL}$ & & 11 & 20 & & $472 \pm 5$ & $325 \pm 6$ \\
\hline LQ & & & $10 \pm 3 *$ & 29 & $498 \pm 7$ & $331 \pm 4$ \\
\hline 2B (QLQL) & 6 & 15 & 24 & & $477 \pm 5$ & $333 \pm 3$ \\
\hline 2K (LQLQ) & & & 12 & 39 & $495 \pm 8$ & $337 \pm 3$ \\
\hline
\end{tabular}

* Average of two measurements. All the other Charpy impact toughness data were from one measurement per condition. The hardness values were average of at least six measurements.

this treatment were used as reference values in later comparison. Since the hardness value is a good representation of the strength level of the alloy, the change of hardness reveals the change of strength.

As can be seen from Table 3, different heat treatments have little influence on the hardness prior to ageing, though hardness of the specimen after $2 \mathrm{~K}$ treatment may be considered marginally higher. The alloys of LQ and $2 \mathrm{~K}$ treatments demonstrated similar ageing behaviour as that of $\mathrm{Q}$ treatment. The $\mathrm{Q}$ treatment provides the highest hardness value after $4 \mathrm{~h}$ at $510^{\circ} \mathrm{C}$, though the hardness values of the alloy of LQ and $2 \mathrm{~K}$ treatments are close considering the range of standard deviations. The hardness values after $4 \mathrm{~h}$ at $510^{\circ} \mathrm{C}$ of the alloy of QL and 2B treatments were lower than those of $\mathrm{Q}, \mathrm{LQ}$ and $2 \mathrm{~K}$ treatments. The expected strength/hardness increase through these treatments was not achieved either before or after ageing. However, the Charpy impact strength was indeed significantly improved. Without significant hardness loss, the LQ and $2 \mathrm{~K}$ treatments provided higher ambient Charpy impact values. The improvement in Charpy impact strength due to QL and $2 \mathrm{~B}$ treatments was more significant. Even when the loss in hardness is considered, these two treatments still provide a good combination of strength and toughness properties, so do the LQ and $2 \mathrm{~K}$ treatments.

\subsection{Microstructure and XRD Results Analysis}

Electro-etching was used to reveal the grain boundaries in the specimens. Microstructures of the specimens after Q, LQ and $2 \mathrm{~K}$ treatments after electro-etching are shown in 


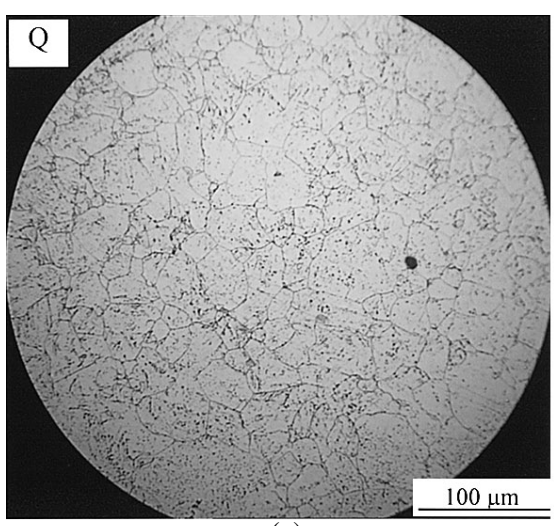

(a)

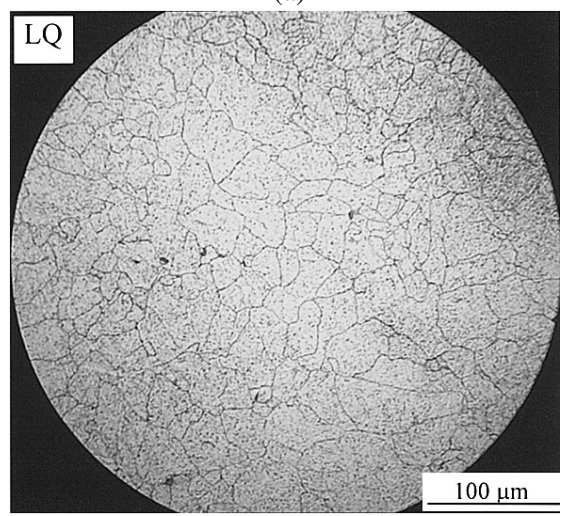

(b)

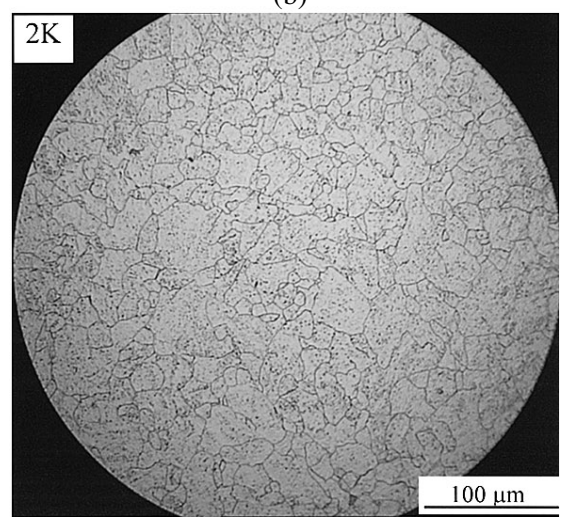

(c)

Fig. 3. Microstructures of the alloy after $\mathrm{Q}(\mathrm{a}), \mathrm{LQ}$ (b) and $2 \mathrm{~K}$ (c) treatments: $2 \mathrm{~K}$ treatment reduces the grain size significantly.

Fig. 3. The grain size estimated by line intercept method is 28,25 and $15 \mu \mathrm{m}$ for Q, LQ and $2 \mathrm{~K}$ treatments, respectively. As can be seen, $2 \mathrm{~K}$ treatment significantly refines the grain size, whereas the refinement effect of LQ treatment is weak. With such obvious refinement effect of $2 \mathrm{~K}$ treatment, it is surprising to see that the hardness of this treatment is not significantly higher than that of the Q and LQ treatments prior to ageing treatment, Table 3 . Such refinement has no significant effect on the hardness during ageing, unlike that observed for $18 \mathrm{Ni} 250$-grade in a previous work where the beneficial effect of grain refinement on hardness/strength was amplified by ageing. ${ }^{9)}$

The optical microstructures of electro-etched samples after QL and 2B treatments are shown in Fig. 4. Although the electro-etching did not reveal the grain boundaries, the microstructure of $2 \mathrm{~B}$ treatment is finer than that of QL treatment. The brighter phase in Fig. 4 does not seem

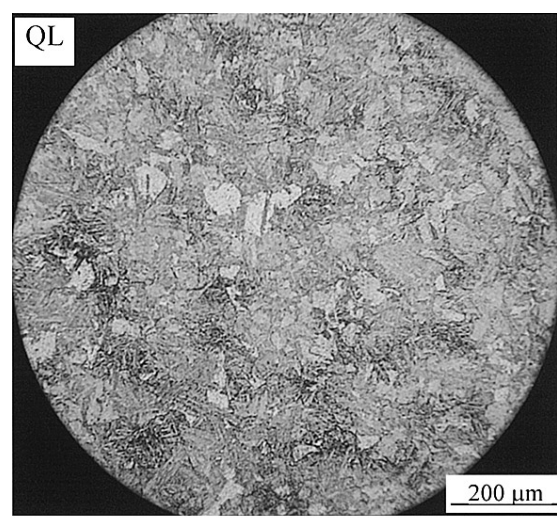

(a)

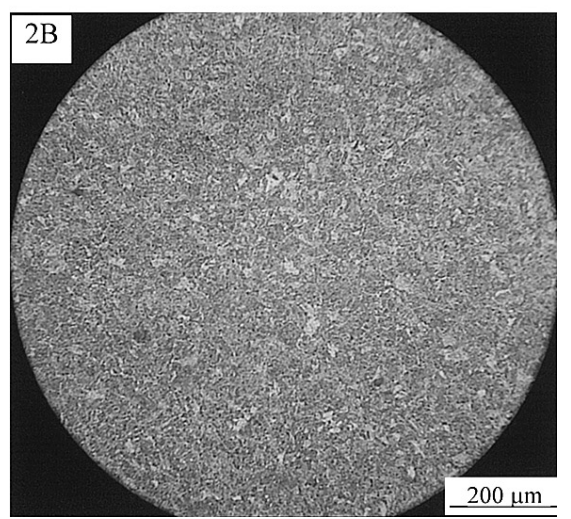

(b)

Fig. 4. Microstructures of the alloy after QL (a) and $2 B(b)$ treatments: fresh martensite and parent martensite have different etching response (electro-etching).

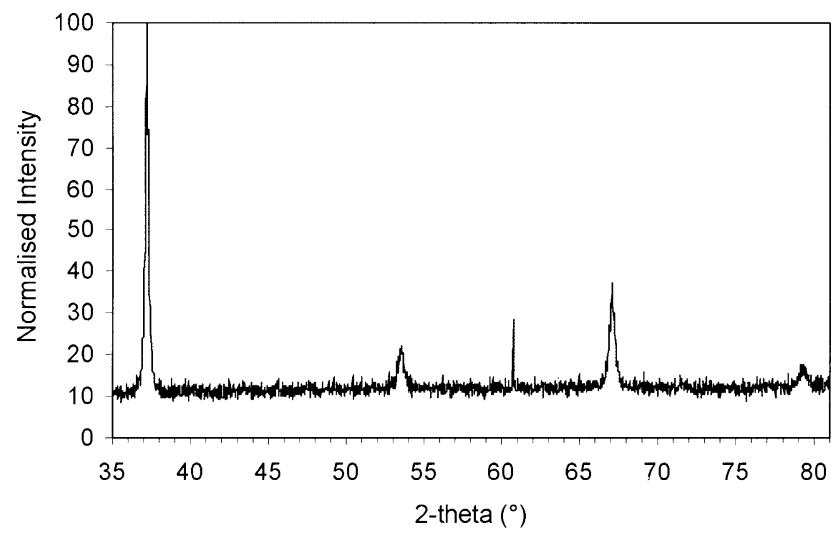

Fig. 5. XRD profile of the alloy after $2 B$ treatment followed by $4 \mathrm{~h}$ at $510^{\circ} \mathrm{C}$ : no reflection peaks of retained/reverted austenite were observed. The sharp peak at $61^{\circ}$ position was from the sample holder.

to be austenite, otherwise such an austenite fraction would have been detected by high-resolution X-ray diffraction (HRXRD) analysis using synchrotron radiation. The fact that no reflection peaks for austenite were observed in HRXRD pattern after $2 \mathrm{~B}$ treatment followed by ageing suggests little austenite retained during the $2 \mathrm{~B}$ treatment, and no reverted austenite formed during $4 \mathrm{~h}$ ageing at $510^{\circ} \mathrm{C}$, Fig. 5. The amount of retained/reverted austenite should be no higher than $0.5 \%{ }^{14)}$ The sharp peak at $61^{\circ}$ was from the sample holder instead of the sample itself. Significant improvement in Charpy impact strength was observed after 

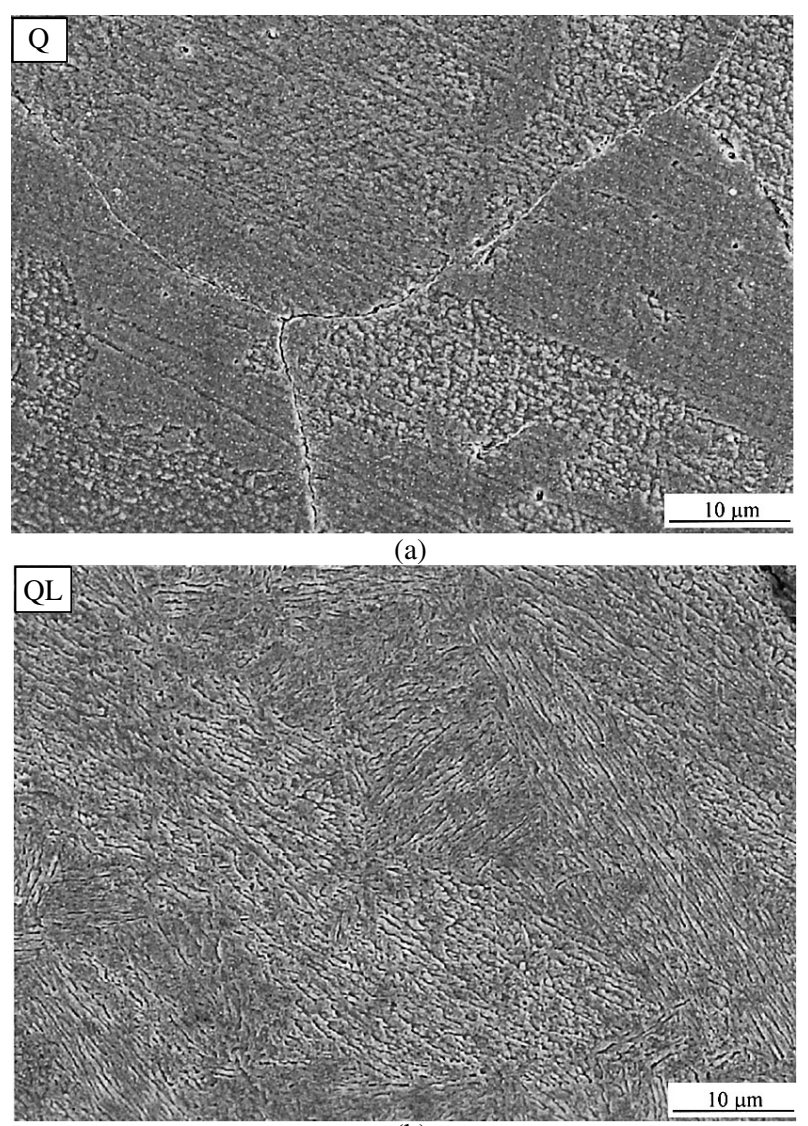

(b)

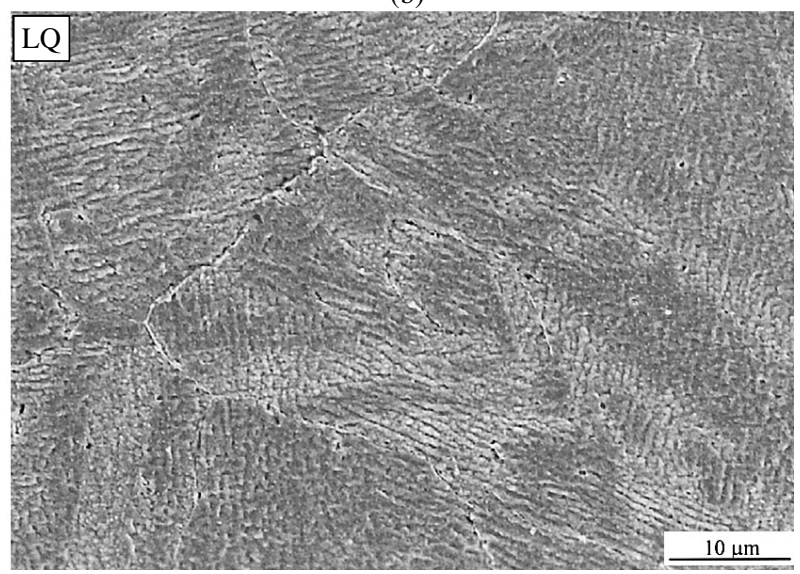

(c)

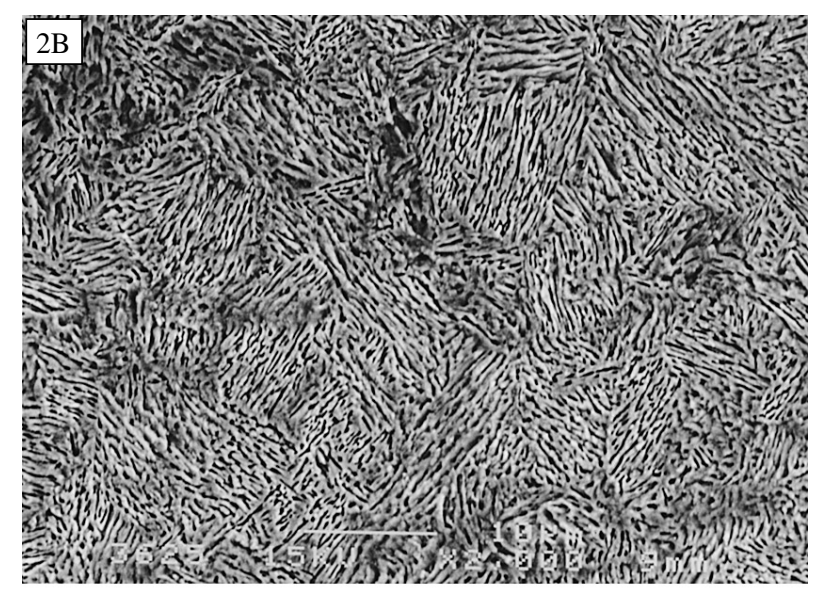

(d)

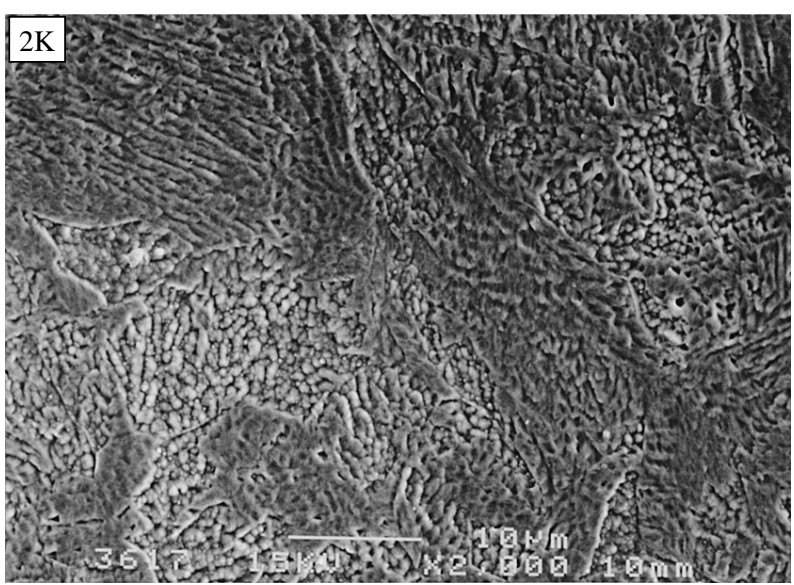

(e)

Fig. 6. SEM pictures of the alloy after Q (a), QL (b), LQ (c), 2B (d), and $2 \mathrm{~K}$ (e) treatments after chemical etching.

ageing the QL- and 2B-treated alloys, Table 3, at little expense of hardness. Considering that retained/reverted austenite normally leads to significant hardness drop, such a dual-phase structure gives better combination of strength/ hardness and toughness properties.

Scanning electron microscopy (SEM) was used to clearly reveal the microstructure of specimens after different treatments, Fig. 6. Specimens were etched chemically after repolishing the electro-etched surface. A clear lath structure is evident with all the SEM micrographs. It should be noted that Figs. 6(a) and 6(e) show two morphologies. It could be that the granular one shows cross section of laths, although this morphology is rarely seen in practice. QL and $2 \mathrm{~B}$ treatments generated similar lath martensitic structures, whereas the martensite packs in Fig. 6(d) is finer than those in Fig. $6(\mathrm{~b})$. The grain size of the $2 \mathrm{~B}$-treated specimen was esti- mated as $10 \mu \mathrm{m}$ from the SEM photo Fig. 6(d), whereas neither optical picture or SEM photo allows an estimation of the grain size in the QL-treated condition. Further discussion on the SEM photos is to be carried out in the following section.

\section{Discussion}

Result analysis shows that improvement in toughness of the PH13-8 stainless steel was achieved through the introduction of intercritical annealing. However, a few questions remained to be answered, which are discussed below.

\subsection{Grain refinement mechanism of intercritical an- nealing}

Intercritical annealing was accomplished by holding the 
alloy in a $(\alpha+\gamma)$ two-phase region and then cooling to room temperature. It forms high volume fraction of alloyrich $\gamma$-phase, reverted austenite and well-tempered, alloylean $\alpha_{\mathrm{t}}$. However, the $\gamma$-phase formed at temperatures near $\mathrm{A}_{\mathrm{c} 3}$ is only slightly enriched in alloy content and largely retransforms during cooling, producing a 'dual-phase' structure that is a mixture of tempered $\left(\alpha_{\mathrm{t}}\right)$ and fresh martensite $\left(\alpha^{\prime}\right)$. While intercritical annealing produces a dual-phase microstructure, it does not significantly refine the grain size, as it can be seen that LQ treatment, Fig. 3(b), shows no clear sign of grain refinement while comparing with Fig. 3(a). The reason is that the austenite precipitated along a lath boundary has a strong tendency to retransform into the particular variant of martensite that defines the surrounding packet. ${ }^{15)}$ However, the martensite packet is chemically heterogeneous after intercritical annealing. The $\alpha_{\mathrm{t}}$ is relatively lean in solute while $\alpha^{\prime}$ is relatively rich. Although this treatment does not refine the grain size, the chemical redistribution sets up the microstructure for effective grain refinement in subsequent steps, as can be seen from the refinement effects of $2 \mathrm{~B}$ and $2 \mathrm{~K}$ treatments.

To understand how intercritical annealing can lead to grain refinement, let L-treated steel be given a reversion $\mathrm{Q}$ treatment. On heating into the austenite field, both constituents of the L-treated steel revert to austenite. However, low diffusivity of the substitutional species in the $\gamma$-phase prevents their homogenisation. The 'dual-phase' character of the alloy is preserved. On subsequent quenching, the 'dual-phase' alloy undergoes a two-step martensitic transformation. The low-alloy constituent transforms first. Since it is constrained by the surrounding austenite during its transformation, it is severely worked, and deforms the austenite in turn. The high alloy phase then transforms, while constrained and deformed by the martensite that has already formed. The result is that the transformation occurs under severe mechanical constraint, which encourages local volumes to transform into the martensite variants that are most compatible with the local stress rather than those that continue the pattern in a martensite packet. The result is a very fine-grained microstructure.

To clarify whether the chemical redistribution resulted from the $\mathrm{L}$ treatment might disappear after the $\mathrm{Q}$ treatment, the diffusion distance of elements $\mathrm{Ni}, \mathrm{Cr}$ and $\mathrm{Mo}$ after $2 \mathrm{~h}$ at $760^{\circ} \mathrm{C}$ or half an hour at $927^{\circ} \mathrm{C}$ was calculated. Results are shown in the Table 4. Diffusion distance $x$ was estimated as $x=\sqrt{D \cdot t}$, where $D=D_{0} \exp (-Q / R T)$. Different diffusion parameters were used for $760^{\circ} \mathrm{C}$ (diffusion in $\alpha$-Fe) and $927^{\circ} \mathrm{C}$ (diffusion in $\gamma-\mathrm{Fe}$ ), respectively. ${ }^{16)}$ One can see that the diffusion distance of the three elements after $2 \mathrm{~h}$ at $760^{\circ} \mathrm{C}$ is longer than that after half an hour at $927^{\circ} \mathrm{C}$, which means that the element redistribution caused by $\mathrm{L}$ treatment cannot be completely erased by the $\mathrm{Q}$ treatment.

\subsection{Relationships among Heat Treatment, Micro- structure, and Mechanical Properties}

Introduction of intercritical annealing in the present work does not always lead to grain refinement. As can be seen, LQ treatment does not have grain refinement effect, Fig. 3(b) in comparison with Fig. 3(a). One possible explanation to the non-refinement is that L-treatment may have not set up the chemical redistribution required for grain refinement
Table 4. Diffusion distance of elements $\mathrm{Ni}, \mathrm{Cr}$ and $\mathrm{Mo}$ : (a) after $2 \mathrm{~h}$ at $760^{\circ} \mathrm{C}$, (b) or half an hour at $927^{\circ} \mathrm{C}$. Different diffusion parameters were used for $760^{\circ} \mathrm{C}$ (diffusion in $\alpha$-Fe) and $927^{\circ} \mathrm{C}$ (diffusion in $\gamma$-Fe), respectively.

(a)

\begin{tabular}{|c|c|c|c|c|c|}
\hline Element & $\begin{array}{c}\mathrm{D}_{0} \\
\left(10^{-4} \mathrm{~m}^{2} / \mathrm{s}\right)\end{array}$ & $\begin{array}{c}\mathrm{Q} \\
(\mathrm{kJ} / \mathrm{mol})\end{array}$ & $\begin{array}{c}\mathrm{D} \\
\left(\mathrm{m}^{2} / \mathrm{s}\right)\end{array}$ & $\begin{array}{c}\text { Temp range } \\
\left({ }^{\circ} \mathrm{C}\right)\end{array}$ & $\begin{array}{c}\text { Diffusion distance for } \\
2 \text { hours at } 760^{\circ} \mathrm{C}(\mu \mathrm{m})\end{array}$ \\
\hline $\mathrm{Ni}$ & 2.41 & 242.2 & $1.37 \times 10^{-16}$ & $800 \sim 900$ & 0.99 \\
\hline $\mathrm{Cr}$ & 2.33 & 238.8 & $1.97 \times 10^{-16}$ & $775 \sim 1698$ & 1.19 \\
\hline $\mathrm{Mo}$ & 0.663 & 224.2 & $3.06 \times 10^{-16}$ & $775 \sim 1509$ & 1.48 \\
\hline
\end{tabular}

(b)

\begin{tabular}{|c|c|c|c|c|c|}
\hline Element & $\begin{array}{c}\mathrm{D}_{0} \\
\left(10^{-4} \mathrm{~m}^{2} / \mathrm{s}\right)\end{array}$ & $\begin{array}{c}\mathrm{Q} \\
(\mathrm{kJ} / \mathrm{mol})\end{array}$ & $\begin{array}{c}\mathrm{D} \\
\left(\mathrm{m}^{2} / \mathrm{s}\right)\end{array}$ & $\begin{array}{c}\text { Temp range } \\
\left({ }^{\circ} \mathrm{C}\right)\end{array}$ & $\begin{array}{c}\text { Diffusion distance for } \\
0.5 \text { hour at } 927^{\circ} \mathrm{C}(\mu \mathrm{m})\end{array}$ \\
\hline $\mathrm{Ni}$ & 0.108 & 273.0 & $1.42 \times 10^{-17}$ & $930 \sim 1356$ & 0.16 \\
\hline $\mathrm{Cr}$ & 0.169 & 263.9 & $5.52 \times 10^{-17}$ & $900 \sim 1345$ & 0.32 \\
\hline $\mathrm{Mo}$ & 0.036 & 239.8 & $1.32 \times 10^{-16}$ & $1050 \sim 1360$ & 0.49 \\
\hline
\end{tabular}

to take place in subsequent steps. This explanation can be tested by studying the influence of lower temperature and/or longer holding time of L-treatment on grain refinement. However, as to be discussed below, the contribution to the better toughness achieved from grain refinement may not be significant, so further research in this direction was not carried out. Even when significant grain refinement was achieved after $2 \mathrm{~B}$ and $2 \mathrm{~K}$ treatments, the hardness values showed little improvement. In fact, when grade 250 maraging steels were studied, Luo et al. reported that both hardness and strength were significantly increased due to grain refinement, ${ }^{9}{ }^{9}$ whereas Ashur et al. found that the grain size has only minor effect on mechanical properties. ${ }^{16)}$ The applicability of the Hall-Petch relationship on hardness/ strength is difficult to evaluate due to the existence of the two types of morphologies. It is possible that a very small amount of austenite formed between martensite laths after $\mathrm{QL}$ and $2 \mathrm{~B}$ treatments. The amount is too small to be detected even by high-resolution X-ray diffraction analysis using synchrotron radiation, Fig. 5. Nevertheless, the lath structures after QL and 2B treatments do appear thinner and shorter than those after Q, LQ and $2 \mathrm{~K}$ treatments.

If one compares the toughness of the alloys after Q, LQ and $2 \mathrm{~K}$ treatments, one can see that grain refinement does not significantly improve the toughness. It is, in fact, when a 'dual-phase' exists, especially when L-treatment is the end treatment, that the toughness was significantly increased. Such a 'dual-phase' structure acts similar to a mixture of martensite and retained/reverted austenite when toughness is concerned, but offers better hardness/strength. Although one cannot completely exclude the possibility that very small amount of austenite, which is not detectable by high-resolution X-ray diffraction analysis, formed during QL and 2B treatments, its contribution to toughness and hardness/strength should be limited.

Dispersion of precipitates may also influence the strength and toughness of the alloy. There are two types of precipitates in the aged PH13-8 alloys. One type is intermetallic compounds and the other is carbides. The intermetallic compounds contribute to the main strengthening effects, and their size is of nanometre scale. Study of the dispersion of such fine particles requires advanced techniques such as atom probe field ion microscopy (APFIM). ${ }^{18)}$ PH13-8 steel achieves its ultra-high strength through intermetallic pre- 
cipitations. The amount of carbon is kept as low as possible to minimise the formation of carbides. Hochanadel et al. observed $\mathrm{M}_{23} \mathrm{C}_{6}$ in a cast $\mathrm{PH} 13-8$ grade of $\mathrm{H} 1150 \mathrm{M}^{19)}$ treatment. ${ }^{20)}$ The $\mathrm{M}_{23} \mathrm{C}_{6}$ particle observed is about $70 \mathrm{~nm}$. No analysis on their distribution was carried out presumably due to its low number density. Usually one would not expect the dispersion of such precipitates to affect the properties very much. Even if their influence is not negligible, it will have similar effects on alloys after different treatments, unless the alloy is heated up to $1038^{\circ} \mathrm{C}$ or over when the particles dissolve and homogenisation is achieved. In other words, the existence of such precipitates would affect the properties of the Q-treated alloy in about the same way as it would for the QL, LQ, QLQL, and LQLQ treated conditions. The existence of such particles may help grain refinement by pinning grain boundaries. However, this is not the main grain refinement mechanism in the present study.

Another fact observed in Fig. 2 is that the maximum hardness is rather low in the QL and QLQL treated specimens. A possible explanation is given below. QL and QLQL treatments result in dual-phase structure. Although both phases are martensitic, they are of slightly different composition. Therefore, the hardness of these two phases may not differ very much, which explains why the priorageing hardness values of different treatments are very close, Table 3. However, in the following ageing treatments, the softer martensite may act like retained austenite, i.e., the strength drop due to its existence may be exaggerated by ageing.

\subsection{Comparison with Commercial H950 Treatment}

PH13-8 alloy after commercial H950 treatment has yield strength $1449 \mathrm{MPa}(210 \mathrm{ksi}$ ), HRC hardness 47 (Vickers hardness $471^{21)}$ ) and Charpy impact strength $27 \mathrm{~J} .{ }^{22}$ The alloy studied in the present work only has Charpy impact strength $5.5 \mathrm{~J}$ after H950 treatment. This value is much smaller than the above reported value even when the size of specimen used in this work is considered. The hardness value HV 516 (HRC 50 $0^{21)}$ ) is higher than that from commercial product data. The reason for such differences is unclear since many factors, such as alloy history, composition and Charpy impact specimen size, may play some roles in affecting properties.

If one compares the properties of the alloy after different treatments, one will see that both $\mathrm{QL}$ and $2 \mathrm{~B}$ treatments offer much higher Charpy impact strength than the commercial H950 treatment. The hardness values after these treatments are very close. The alloy after $2 \mathrm{~B}$ treatment may be used when temperature is under $-40^{\circ} \mathrm{C}$. QL treatment, adding one intercritical annealing step to the commercial H950 treatment, offers a competitive combination of hardness and Charpy impact strength. While H1000 treatment offers similar Charpy impact strength, the hardness is only HV 446 (HRC 45), much lower than that of QL treatment (HV 472). 2B, i.e. QLQL, which offers better combined properties than QL, might be less cost-effective due to its complex heat treatment steps. LQ and $2 \mathrm{~K}$ treatments improve the Charpy impact strength when hardness is largely maintained. They may provide alloys of similar toughness but higher hardness than the commercial treatment. $2 \mathrm{~K}$ treatment, i.e. LQLQ, might be less cost-effective due to its complex heat treatment steps. The microstructure with 'dual-phase' feature might also have superior corrosion resistant properties, as dual phase steels have been proven to have superior corrosion resistant properties. In conclusion, $\mathrm{QL}, 2 \mathrm{~B}$, LQ and $2 \mathrm{~K}$ treatments all provide better combination of properties than the commercial treatment. Which one is to be used depends on the application requirements as well as the justification for cost. Since thermal cycling treatment is a costly procedure, ${ }^{23)}$ simple treatment procedures LQ and QL may be more applicable economically.

\section{Conclusions}

An intercritical annealing step was introduced in the treatment of a PH13-8 alloy, resulting in four different treatment cycles, i.e., austenitisation (Q) and intercritical annealing (L), LQ, 2B (QLQL) and 2K (LQLQ), where Q denotes $0.5 \mathrm{~h}$ at $927^{\circ} \mathrm{C}$ followed by water quenching, and $\mathrm{L}$ denotes $2 \mathrm{~h}$ at $760^{\circ} \mathrm{C}$ followed by air cooling. Significant grain refinement effect was observed after $2 \mathrm{~B}$ and $2 \mathrm{~K}$ treatments. Although such refinement of prior austenite grain did not lead to significant increase of hardness either before or after ageing, the Charpy impact strength of the aged sample was improved. No retained/reverted austenite was observed in the aged specimens. Result analysis also shows that although grain refinement may improve the alloy's toughness, the main contribution is thought to be due to the 'dual-phase' martensitic structure formed during L-treatment. Such a 'dual-phase' structure may provide better combined properties than the usual martensite plus retained/reverted austenite mixture. All the four treatments offer better combined properties than the commercial treatment. QL and LQ treatments may be cost-competitive.

\section{Acknowledgements}

Dr. S. Malinov at Queen's University of Belfast is thanked for his help with X-ray diffraction analysis using synchrotron radiation and useful discussions. Ms. W. Beck at Allvac U.K. Ltd. provided the PH13-8 alloy. Ms J. Patrick and Mr. S. McFarland in Electron Microscopy Unit at Queens University of Belfast are also thanked for their technical assistance. Dr. Sha's contribution to this work is sponsored under The Royal Academy of Engineering's Global Research Award Scheme. This work was carried out within the project of 'Computer Modelling of the Evolution of Microstructure during Processing of Maraging Steels' sponsored by the Engineering and Physical Sciences Research Council, UK, under Grant No. GR/N08971.

\section{REFERENCES}

1) B. Pollard: ASM Handbook, Vol.6, ASM, Materials Park, OH, (1993), 482.

2) S. Jin, J. W. Morris, Jr. and V. F. Zackay: Metall. Trans. A, 6A (1975), 141.

3) S. Jin, S. K. Hwang and J. W. Morris, Jr.: Metall. Trans. A, 6A (1975), 1721

4) C. K. Syn, S. Jin and J. W. Morris, Jr.: Metall. Trans. A, 7A (1976), 1827.

5) S. K. Hwang and J. W. Morris, Jr.: Metall. Trans. A, 10A (1979), 545.

6) M. Nasim and E. A. Wilson: Phase Transformations, Vol. I, The Institute of Metallurgists, York, (1979), v-21.

7) U. K. Viswanathan, R. Kishore and M. K. Asundi: Metall. Mater. 
Trans. A, 27A (1996), 757.

8) A. Goldberg: Source Book on Maraging Steels, ed. by R. F. Decker, ASM, Metals Park, OH, (1979), 41.

9) H. Luo, Z. Yin, J. Zhu, M. Li, H. Li, H. Guo, H. Fang, Z. Lai and Y. Liu: Cailiao Kexue Yu Gongyi (Mater. Sci. Technol.) (China), (2000), No. 1, 59.

10) G. Saul, J. A. Roberson and A. M. Adair: Source Book on Maraging Steels, ed. by R. F. Decker, ASM, Metals Park, OH, (1979), 52.

11) Z. Guo, K. Sato, T. K. Lee and J. W. Morris, Jr.: Ultrafine Grained Materials, eds. by R. S. Mishra, S. L. Semiatin, C. Suryanarayana, N. N. Thadhanis, T. C. Lowe, TMS, Warrendale, PA, (2000), 51.

12) H. J. Kim, Y. H. Kim and J. W. Morris, Jr.: ISIJ Int., 38 (1998), 1277.

13) J. W. Morris, Jr., Z. Guo and C. R. Krenn: Steel Heat Treating in the New Millennium-An International Symposium in Honor of George Krauss, ASM International, Materials Park, OH, (2000), 526.

14) S. Malinov: private communication, Queen's University of Belfast, U.K., (2003).
15) C. K. Syn, B. Fultz and J. W. Morris, Jr.: Metall. Trans. A, 9A (1978), 1635.

16) A. Ashur and A. Rosen: Strength of Metals and Alloys, Vol. 2, Freund Publishing House, London, (1991), 1019.

17) H. Oikawa: Review on Lattice Diffusion of Substitutional Impurities in Iron-A Summary Report, http://inaba.nims.go.jp/diff/ DIF_Oikawa/Table.html, (accessed March 2003).

18) Z. Guo, W. Sha and D. Vaumousse: Acta Mater, 51 (2003), 101.

19) C. V. Robino, P. W. Hochanadel, G. R. Edwards and M. J. Cieslak: Metall. Mater. Trans. A, 25A (1994), 697.

20) P. W. Hochanadel, C. V. Robino, G. R. Edwards and M. J. Cieslak: Metall. Mater. Trans. A, 25A (1994), 789.

21) Eagle International Software Inc., http://my.metalinfo.com $/ \mathrm{mm}_{\text {- }}$ utilities/hardnesschart.cfm, (accessed September 2002).

22) Alloy Data for Carpenter PH13-8 Mo Stainless Steel, Carpenter Technology Corporation, Wyomissing, PA, (2001).

23) W. Beck: private communication, Allvac Ltd. U.K., (2000). 